\title{
Diagnóstico do conhecimento de informações básicas para o uso de agrotóxicos por produtores de hortaliças da Região de Londrina
}

\section{Diagnosis of the knowledge of basic informations for the usage of pesticides by vegetable growers in Londrina Region}

\author{
Camila Renata Gonçalves Marques ${ }^{1 *}$; Pedro Manuel Oliveira Janeiro Neves ${ }^{2}$; \\ Maurício Ursi Ventura ${ }^{3}$
}

\begin{abstract}
Resumo
O rótulo e a bula dos agrotóxicos contêm informações sobre a utilização correta e segura destes compostos. O entendimento dos mesmos é importante para a prevenção e redução no número de intoxicações ocupacionais. Este trabalho teve por objetivo diagnosticar o conhecimento de informações básicas para o uso de agrotóxicos por produtores rurais de hortaliças da região de Londrina, dando ênfase ao entendimento dos rótulos e bulas pelos mesmos. Para isso, utilizou-se como instrumento de pesquisa, questionário aplicado a produtores rurais cadastrados na Central de Abastecimento do Paraná (CEASA) da cidade de Londrina. Foram abordadas questões relacionadas a intoxicações, uso de equipamentos de proteção individual e entendimento dos rótulos e bulas. As maiores dificuldades foram a compreensão do conteúdo (linguagem técnica) e o tamanho reduzido das letras. Os pictogramas, as faixas de cores e termos importantes para a segurança na utilização de agrotóxicos não foram compreendidos pela maioria dos agricultores. Os inseticidas foram os produtos mais utilizados e responsáveis pelo maior número de intoxicações.

Palavras-chave: Intoxicação, segurança ocupacional.
\end{abstract}

\begin{abstract}
The label and the bull of pesticides contain informations about the suitable and secure usage of these compounds. The understanding of these materials is important to prevent and reduce occupational intoxications. This study deals with the diagnosis of the knowledge and understanding the basic information contained in the label of the packages by vegetable growers (mostly small) from Londrina, PR. A form was applied to growers registered at the Central de Abastecimento do Paraná (CEASA) at Londrina, about intoxications, individual protection equipment and comprehension of labels and bulls. Greater difficulties were the comprehension of the content (technical language) and the reduced size of the letters. The pictograms, color ranges and terms for the safe use of pesticides were not understood by most farmers. Inseticides were the most used and were responsible for most poisonings.
\end{abstract}

Key words: Intoxication, occupational security

\footnotetext{
1 Eng ${ }^{\circ}$ Agr $^{\circ}$, Msc. em Agronomia pela Universidade Estadual de Londrina. Caixa Postal 6001, 86051-990, Londrina, PR. E-mail: camilargmarques@yahoo.com.br

$2 \mathrm{Eng}^{\mathrm{o}} \mathrm{Agr}^{\mathrm{o}}$, Dr. em Entomologia, Professor Adjunto do Departamento de Agronomia, Centro de Ciências Agrárias, da Universidade Estadual de Londrina. Londrina, PR. E-mail: pedroneves@uel.br

3 Eng $^{\circ}$ Agr $^{\circ}$, Doutor em Ciências Biológicas -Entomologia, Professor Adjunto do Departamento de Agronomia, Centro de Ciências Agrárias, da Universidade Estadual de Londrina. Londrina, PR. E-mail: mventura@uel.br

* Autor para correspondência
} 


\section{Introdução}

Os agrotóxicos passaram a ser produzidos mundialmente e em grande escala, nos anos 40, a partir da segunda guerra mundial, onde foram utilizados como arma química (OPAS/OMS, 1996). A Revolução Verde, processo de modernização tecnológica, iniciado nos anos 50, modificou profundamente as práticas agrícolas (BRUM, 1988), gerou mudanças ambientais, nas cargas de trabalho, na utilização de agrotóxicos na agricultura e nos seus efeitos sobre a saúde, deixando os trabalhadores rurais expostos a riscos diversificados (FARIA et al., 2000).

O Brasil possui a maior utilização de agrotóxicos da América Latina, com uso estimado em $50 \%$ da quantidade comercializada nesta região, Garcia (1997)apudOliveira-Silvaetal.(2001).Ahorticultura é responsável por grande parte da utilização destes produtos, pois as pulverizações para o controle de pragas e doenças em algumas culturas são realizadas semanalmente (ARAÚJO et al., 2000; ALMEIDA; CARNEIRO; VILELA, 2009). Este fato aumenta a exposição dos trabalhadores rurais a estes produtos e a riscos de intoxicações.

$\mathrm{O}$ número de intoxicações e óbitos de contaminação por agrotóxicos são preocupantes em todo o mundo. Dados da Organização Mundial da Saúde estimam que ocorram no mundo cerca de três milhões de intoxicações por agrotóxicos, com 220 mil mortes por ano, sendo $70 \%$ nos países em desenvolvimento. De acordo com a Confederação Nacional dos Trabalhadores na Agricultura (CONTAG) o número de intoxicações chega a 800 mil casos por ano no Brasil (CONTAG, 2005). No Estado do Paraná, 14,3 mil pessoas foram intoxicadas por agrotóxicos, com registros de 1439 óbitos entre os anos de 1986 a 2004, com média de 754 casos de intoxicação e 75 óbitos por ano (SECRETARIA DE ESTADO DE SAÚDE DO PARANÁ, 2005). Este quadro pode estar subestimado considerando que, de acordo com estimativas do Ministério da Saúde, para cada evento notificado de intoxicação por agrotóxicos, há cerca de 50 não notificados (CASADO, 2005). As classificações de intoxicação por agrotóxicos podem ser divididas em: a) aguda, que é determinada por sintomas nítidos que surgem rapidamente; b) subcrônica, que ocorre por exposição moderada ou pequena a produtos altamente tóxicos ou medianamente tóxicos, cujos sintomas são subjetivos como dor de cabeça, fraqueza, entre outros e; c) crônica, que se caracteriza por surgimento tardio, após meses ou anos, por exposição curta ou moderada a produtos tóxicos ou a múltiplos produtos (OPAS/OMS, 1996).

Sabe-seque omanuseiode produtos fitossanitários deve ser realizado por pessoas adultas, alfabetizadas e bem informadas sobre os riscos. A melhor fonte de informação sobre o produto é o rótulo e a bula (ANDEF, 2005). Os rótulos dos agrotóxicos trazem informações a respeito do grupo químico, ingrediente ativo do produto e informações necessárias para que os produtos sejam utilizados adequadamente a fim de evitar intoxicações, como equipamentos de proteção individual (E.P.I.s) a serem utilizados e grau de periculosidade. No entanto, já foi verificado em alguns locais do país que produtores, ao aplicarem os inseticidas, não utilizam os EPIs necessários, o que gera intoxicações (ARAÚJO et al., 2000).

Estudos que avaliam o grau de entendimento dos rótulos dos agrotóxicos pelos agricultores possuem importância para que metas possam ser estabelecidas para viabilizar programas visando à redução de intoxicações. Este trabalho teve por objetivo diagnosticar o conhecimento de informações básicas para o uso de agrotóxicos por produtores rurais de hortaliças da região de Londrina, dando ênfase ao entendimento dos rótulos e bulas pelos mesmos.

\section{Material e Métodos}

O trabalho foi realizado na Central de Abastecimento do Paraná (CEASA) da cidade de Londrina, no ano de 2005, utilizando, como instrumento de pesquisa, questionário (Tabela 1) que 
foi aplicado a trabalhadores rurais cadastrados no referido centro de abastecimento, que liam rótulos de agrotóxicos, encarregados ou não pela aplicação dos mesmos. Foram entrevistados 60 trabalhadores escolhidos ao acaso, de uma população total de 1470 produtores cadastrados no CEASA de Londrina.

Tabela 1. Questionário aplicado aos produtores na Central de Abastecimento do Paraná (CEASA) - Londrina, 2005.

\begin{tabular}{|c|c|}
\hline Pergunta & Opções \\
\hline Lê os rótulos e bulas de agrotóxicos? & Sim - Não (finalizar entrevista) \\
\hline Faz as aplicações de agrotóxicos? & Sim - Não \\
\hline Nome: (opcional); idade; grau de escolaridade; renda. & - \\
\hline Tamanho da propriedade. & $\begin{array}{l}\text { até } 5 \text { ha; de } 5 \text { a } 10 \text { ha; de } 11 \text { a } 50 \text { ha; de } 51 \\
\text { a } 100 \text { ha; mais de } 100 \text { ha }\end{array}$ \\
\hline $\begin{array}{l}\text { Região (localização); culturas; produção; tempo na atividade; tem } \\
\text { funcionários ou possui mão-de-obra familiar }\end{array}$ & - \\
\hline $\begin{array}{l}\text { Quanto tempo de CEASA? Possui assistência técnica? } \\
\text { Possui filiação em cooperativa? }\end{array}$ & - \\
\hline $\begin{array}{l}\text { Tipos de produtos que aplica. Qual destes tem maior uso? (colocar } \\
\text { em ordem decrescente). }\end{array}$ & Herbicidas; fungicidas; inseticidas; outros. \\
\hline Possui local apropriado para armazenamento dos agrotóxicos? & - \\
\hline O que faz com as embalagens de agrotóxicos vazias? & - \\
\hline Qual a tecnologia de aplicação utilizada? & - \\
\hline $\begin{array}{l}\text { O Sr. faz anotações de datas, horários, produtos e etc... das } \\
\text { aplicações? }\end{array}$ & - \\
\hline $\begin{array}{l}\text { Quais das seguintes informações considera que são mais importantes } \\
\text { sobre agrotóxico. Enumere em ordem decrescente de acordo com a } \\
\text { importância na sua opinião (mais de } 1 \text { alternativa). }\end{array}$ & $\begin{array}{l}\text { o que controla; período de carência; } \\
\text { validade; dosagem; toxicidade; E.P.I } \\
\text { necessário; outros }\end{array}$ \\
\hline
\end{tabular}

\section{Rótulos e bulas}

As informações contidas no rótulo são facilmente compreendidas? Se não, qual a principal dificuldade encontrada para entendimento do rótulo?

Qual a primeira informação que o senhor lê?

Sabe o significado das diferentes cores de faixas?

Sabe o que é E.P.I?

Compreende essas ilustrações?

Dados demonstram que muitos trabalhadores rurais não utilizam o E.P.I completo por desconforto, calor ou por considerar um exagero. (induzir resposta sincera). O Sr. utiliza E.P.I completo?

Perguntar sobre as cores novamente, mostrando o rótulo e pedindo para correlacionar as colunas.

Já se sentiu mal durante ou após a aplicação de agrotóxicos?

Sim - Não

Sim - Não

Sim - Não

Mostrar ilustrações de E.P.I e pedir para correlacionar.

Sim - Não, porque? Quais utiliza?

Já se intoxicou?

Sim, quais os sintomas? Não

( ) Sim, qual a providência tomada?

Procurou auxílio médico ou o Sr. se automedicou? Se sim, ficou internado? Com qual produto se intoxicou? ( ) Não 
Por meio de uma pergunta filtro, foram selecionados somente os trabalhadores que liam os rótulos e as bulas das embalagens de agrotóxicos. Após, uma carta de apresentação era fornecida ao entrevistado para o esclarecimento do objetivo do trabalho.

O questionário teve ênfase no entendimento dos rótulos dos agrotóxicos pelo trabalhador rural, abrangendo não somente o conteúdo escrito, mas também as ilustrações contidas nestes rótulos (cores e figuras dos equipamentos de proteção individual), sendo composto por questões de múltipla escolha e abertas, incluindo questões em que rótulos de agrotóxicos foram apresentados ao entrevistado para que fossem feitas correlações, a fim de testar seu conhecimento sobre as faixas de cores e pictogramas contidos; ocorrências de intoxicações; providências tomadas; se o uso dos E.P.I.s está sendo realizado de forma correta; e, questões para caracterizar o perfil do entrevistado como idade, nível de escolaridade e renda.

Os dados coletados foram organizados e tabulados. Utilizou-se a porcentagem para representar a proporção dos mesmos.

\section{Resultados e Discussão}

\section{Aspectos Sócio-Econômicos dos Entrevistados}

Em relação à faixa etária, 36,7\% dos entrevistados estavam na faixa de 26 a 35 anos, $21,7 \%$ de 36 a 45 anos, $20 \%$ de 46 a 55 anos, $15 \%$ de 56 a 65 anos e $6,6 \%$ de 16 a 25 anos (Figura1).

O tamanho das propriedades se concentrou principalmente entre 11 a 50 ha $(51,7 \%)$, seguidos por propriedades nas faixas de 5 a 10 ha $(20 \%)$, até 5 ha $(18,3 \%), 51$ a 100 ha $(6,7 \%)$ e mais de 100 ha $(3,3 \%)$ (Figura 2).

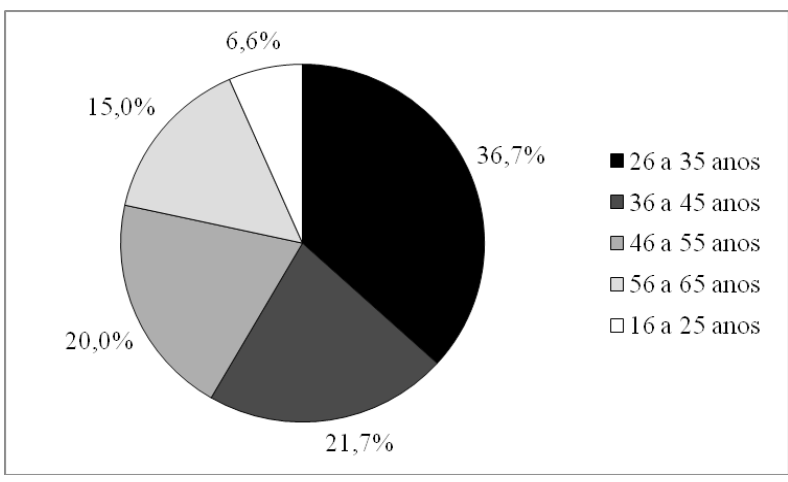

Figura 1. Faixa etária dos produtores de hortaliças entrevistados sobre o conhecimento de informações básicas para o uso de agrotóxicos na CEASA, Londrina, 2005.

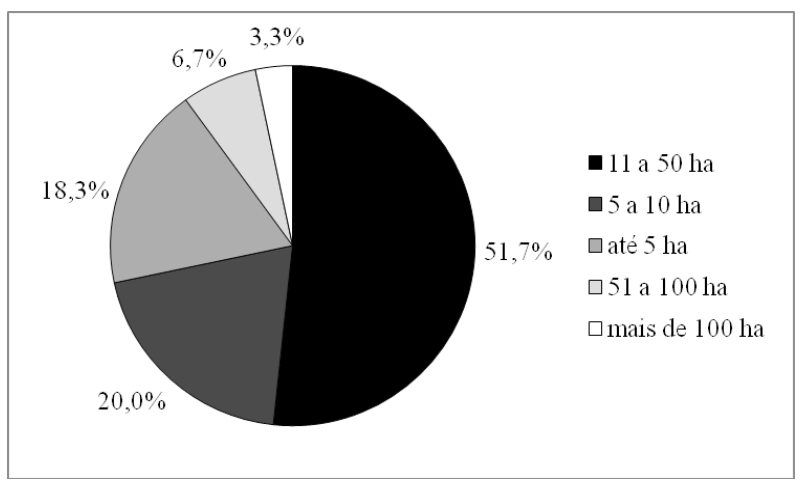

Figura 2. Tamanho da propriedade dos produtores de hortaliças entrevistados sobre o conhecimento de informações básicas para o uso de agrotóxicos na CEASA, Londrina, 2005.

A renda mensal de $76,6 \%$ dos entrevistados situou-se na faixa de 1 a 5 salários mínimos; $20 \%$ apresentaram renda entre 6 a 10 salários mínimos por mês; $1,7 \%$ de 11 a 15 salários mínimos e 1,7\% mais de 15 salários mínimos (Figura 3).

Em relação à escolaridade, $36,7 \%$ dos entrevistados possuíam o ensino médio completo, $30 \%$ o ensino fundamental incompleto, $25 \%$ o ensino fundamental completo, $5 \%$ o ensino médio incompleto e $3,3 \%$ curso superior incompleto ou completo (Figura 4). 


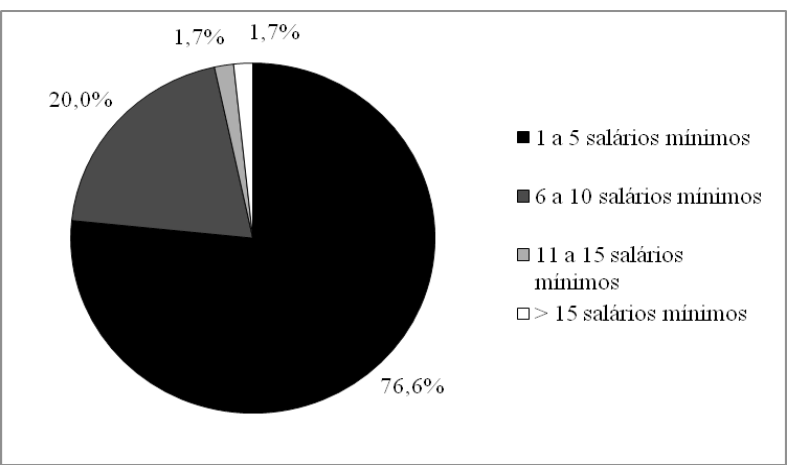

Figura 3. Renda Mensal dos produtores de hortaliças entrevistados sobre o conhecimento de informações básicas para o uso de agrotóxicos na CEASA, Londrina, 2005.

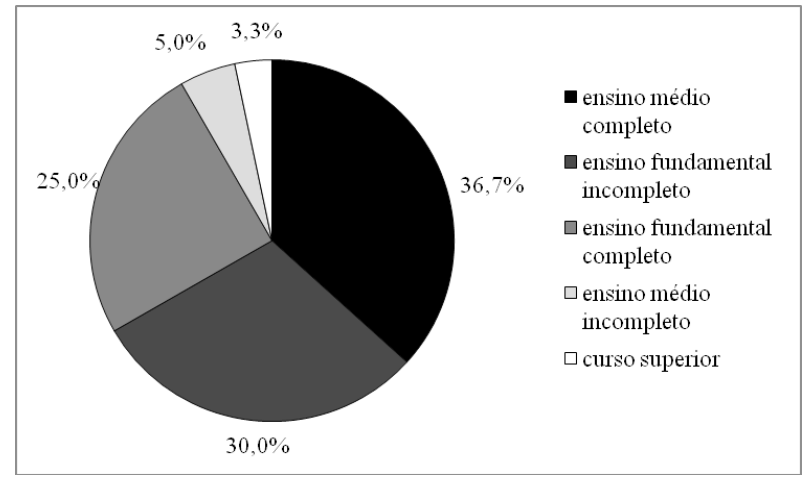

Figura 4. Grau de escolaridade dos produtores de hortaliças entrevistados sobre o conhecimento de informações básicas para o uso de agrotóxicos na CEASA, Londrina, 2005.

\section{Agrotóxicos, EPIs e Descarte de Embalagens}

Do total de entrevistados, $66,7 \%$ realizavam aplicação de agrotóxicos na propriedade e 33,3\% somente liam as informações dos rótulos e passavam as instruções para os encarregados pela aplicação. Porém 30\% das pessoas que aplicavam agrotóxicos não utilizavam E.P.I.s e $75 \%$ das que utilizavam E.P.I.s (70\%) não faziam o uso completo, de acordo com as exigências do produto. Em estudos anteriores a este, valores similares foram observados para produtores de fumo $(26,6 \%)$ que também não utilizavam nenhum tipo de E.P.I. durante as aplicações de agrotóxicos. Isto foi constatado em entrevistas realizadas por Agostinetto et al. (1998) no município de Pelotas, Rio Grande do Sul.

Os E.P.I.s mais utilizados pelos entrevistados que os utilizavam incompletos foram: luvas (76,2\%); máscara $(52,4 \%)$; botas $(38,1 \%)$, macacão, avental e óculos (23,8\%); chapéu e boné árabe (14,3\%). Os principais motivos do não uso ou uso incompleto de E.P.I.s foram: calor $(60,6 \%)$, desconforto $(57,6 \%)$, não acham necessário (24,2\%); sendo o descuido e a falta de tempo os motivos menos citados (3,3\%). Agostinetto et al. (1998) também relataram entre os principais motivos da falta de uso de E.P.I.s o desconforto. Delgado e Paumgartten (2004) ao entrevistarem 52 agricultores do município de Paty do Alferes, Rio de Janeiro, verificaram que 92\% dos entrevistados não faziam uso EPIs durante a preparação e aplicação das caldas. Os motivos citados pelos autores foram semelhantes aos verificados no presente estudo, destacando-se calor e desconforto.

A maioria dos produtores (75\%) afirmou saber as principais vias de absorção de agrotóxicos pelo ser humano (pele, olhos, nariz e boca), mas somente $6,7 \%$ dos entrevistados citaram todas elas.

Dos entrevistados que não realizavam aplicação de agrotóxicos, ou seja, que apenas liam os rótulos, todos afirmaram passar as informações lidas para os responsáveis pela aplicação. A principal informação passada ao aplicador foi a dosagem (70\%) (Tabela 2). Ainda em relação aos mesmos entrevistados, 90\% afirmaram disponibilizar os E.P.I.s necessários aos aplicadores. Os demais 10\% alegaram não disponibilizar os E.P.I.s porque os aplicadores não utilizam, por não achar necessário. Entre as pessoas que disponibilizavam E.P.I.s, 77,8\% exigiam o uso pelos aplicadores e $22,2 \%$ delas não exigiam, deixando a responsabilidade para o aplicador. 
Tabela 2. Informações dos rótulos e bulas de agrotóxicos passadas aos responsáveis pelas pulverizações, pelos produtores de hortaliças entrevistados na CEASA que não manuseavam estes produtos, Londrina, 2005.

\begin{tabular}{lc}
\hline Informações & \% de citações \\
\hline Dosagem & $70 \%$ \\
Cuidados & $35 \%$ \\
E.P. I necessários & $25 \%$ \\
O que controla & $20 \%$ \\
Formas de aplicação & $10 \%$ \\
\hline
\end{tabular}

Com as entrevistas constatou-se que $48,3 \%$ dos entrevistados eram filiados de cooperativas, $85 \%$ recebiam assistência técnica da cooperativa ou da EMATER e $15 \%$ não possuíam nenhum tipo de assistência técnica.

Dos produtores entrevistados, 90\% afirmaram realizar o descarte das embalagens de agrotóxicos de maneira correta, ou seja, devolução da embalagem seguindo os procedimentos recomendados, porém, $3,3 \%$ afirmaram queimar as embalagens após o uso. $\mathrm{O}$ armazenamento na propriedade em locais ou em embalagens impróprias e descarte em lixo comum foram citados por $6,7 \%$ dos entrevistados. Muitos entrevistados mencionaram possuir dificuldade de acesso ao local de devolução das embalagens, como longa distância da propriedade até o ponto de devolução, o que gera despesas, motivo que não incentiva a devolução da embalagem. Os entrevistados esperam apoio e colaboração dos locais de venda de agrotóxicos para o descarte correto de embalagens de agrotóxicos. Uma sugestão foi a de que todos os pontos de venda de agrotóxicos fossem também pontos de recebimento e devolução, facilitando o descarte pelo produtor.

Os locais de aquisição de agrotóxicos pelo produtor foram revendas (48\%) e cooperativas (35\%) e $17 \%$ adquiriam os produtos em ambos os estabelecimentos, sendo que $95 \%$ consultavam um engenheiro agrônomo na hora da compra.

O armazenamento dos agrotóxicos em local exclusivo e trancado é realizado por $98,3 \%$ dos entrevistados, porém $1,7 \%$ faziam o armazenamento em local impróprio, como por exemplo, dentro de casa. Porém Monqueiro, Inácio e Silva (2009) verificaram que uma porcentagem menor de produtores, apenas $48,1 \%$ dos entrevistados, fazia o armazenamento destes produtos corretamente.

Anotações relacionadas à aplicação de agrotóxicos eram feitas por apenas 38,3\% dos entrevistados, e entre as informações mais anotadas estão: data de aplicação $(82,6 \%)$ e produto aplicado $(65,2 \%)$ (Tabela 3$)$.

Tabela 3. Informações mais anotadas pelos produtores de hortaliças entrevistados sobre o conhecimento de informações básicas para o uso de agrotóxicos na CEASA, Londrina, 2005.

\begin{tabular}{lc}
\hline \multicolumn{1}{c}{ Anotações citadas } & $\begin{array}{c}\text { \% dos entrevistados } \\
\text { fazem anotações }\end{array}$ \\
\hline Data & $82,61 \%$ \\
Produto & $65,21 \%$ \\
Horário & $17,39 \%$ \\
Dosagem & $13,04 \%$ \\
Quantidade/ área & $4,34 \%$ \\
Diárias dos trabalhadores & $4,34 \%$ \\
Carência & $4,34 \%$ \\
Infestação & $4,34 \%$ \\
\hline
\end{tabular}

A freqüência de aplicação de agrotóxicos nas propriedades era na maior parte realizada várias vezes por semana $(36,7 \%)$, seguidos por $28,3 \%$ a cada duas semanas, 21,6\% uma vez por semana, $6,7 \%$ aplicavam uma vez por mês ou menos e $6,7 \%$ duas vezes por semana.

Casos de intoxicações foram constatados principalmente em aplicadores que utilizavam EPI incompleto ou não os utilizavam, porém o conceito de intoxicação não estava claro aos trabalhadores que consideravam como intoxicação somente os casos em que precisaram de socorro médico. Indisposições durante ou após aplicações não foram indicados como sinal de intoxicação na opinião dos entrevistados. Com isso, $47 \%$ dos entrevistados 
que aplicavam agrotóxicos, sentiram algum tipo de mal-estar, como ardência nos olhos, tontura, náusea, vômito, salivação, amargor na boca, dor de cabeça, sonolência, moleza no corpo e dor no fígado. Este fato ocorreu também com fumicultores entrevistados por Agostinetto et al. (1998) no município de Pelotas (RS), onde $27,7 \%$ dos produtores entrevistados sentiram algum tipo de mal-estar após as aplicações de agrotóxicos.

Dos produtores que aplicavam agrotóxicos $20 \%$ afirmaram que já se intoxicaram, sendo que destes, $62,3 \%$ procuraram auxílio médico e necessitaram de internação. Os produtos de maior uso entre os entrevistados foram os inseticidas (60\%) (Figura 5), sendo estes responsáveis por $75 \%$ das intoxicações, corroborando com Agostinetto et al. (1998) e Oliveira-Silva et al. (2001), que se referem aos inseticidas como responsáveis pelo maior número de intoxicações. Este fato é preocupante, pois intoxicações por inseticidas organofosforados nas regiões Sul e Nordeste vem sendo relacionadas ao elevado número de suicídios nestas regiões (BLECHER, 1996).

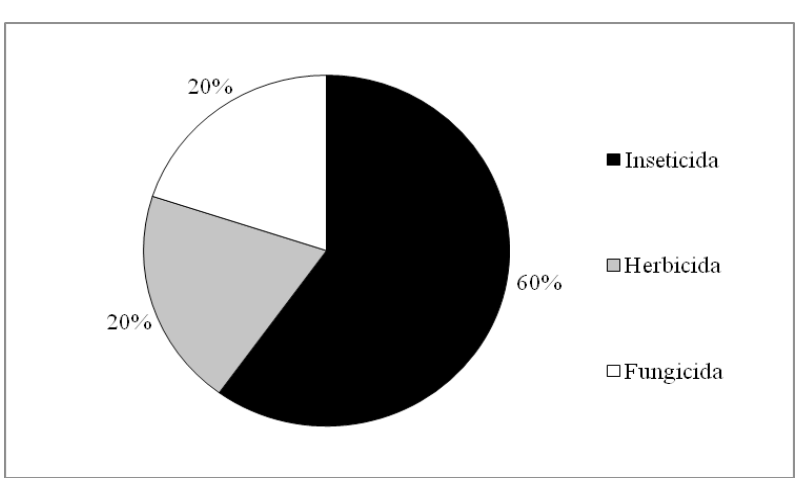

Figura 5. Proporção de agrotóxicos de maior uso entre os produtores de hortaliças entrevistados sobre o conhecimento de informações básicas para o uso de agrotóxicos na CEASA, Londrina, 2005.

\section{Entendimento dos Rótulos de Agrotóxicos}

Dos entrevistados, 60\% afirmaram entender o conteúdo dos rótulos deagrotóxicos sem dificuldades, porém quando alguns termos utilizados nos rótulos lhes foram apresentados, como intervalo de reentrada, período de carência, classe toxicológica, antídoto e sintomas de alarme, apenas $11,1 \%$ dos que afirmaram entender os rótulos acertaram o significado de todos os termos apresentados. O termo com mais acertos de definição foi período de carência com $80,6 \%$ de acertos. Classe toxicológica, sintomas de alarme, antídoto e intervalo de reentrada tiveram $47,2 \%, 41,7 \%, 30,8 \%$ e $25 \%$ de acertos, respectivamente. Dentre as pessoas que acertaram a definição de todos os termos, $50 \%$ possuíam o $1^{\circ}$ grau completo, $25 \%$ possuíam o $2^{\circ}$ grau completo e $25 \%$ possuíam $1^{\circ}$ grau incompleto.

Estudos demonstram que o baixo nível de escolaridade é um dos fatores que contribuem para o risco de intoxicações por agrotóxicos devido a dificuldades na interpretação das recomendações de segurança contidas nos rótulos (AGOSTINETTO et al., 2000; OLIVEIRA-SILVA et al., 2001; FARIA et al., 2004). Este fato não foi verificado no presente estudo, possivelmente devido ao universo de pessoas entrevistadas que não permitiu verificar relação entre o grau de escolaridade e o entendimento das informações contidas nos rótulos.

Percebeu-se que $89,9 \%$ dos produtores que afirmaram entender os rótulos, não souberam a definição de muitos termos importantes para sua própria segurança e dos consumidores. Isto se deve possivelmente, não ao interesse do produtor, mas à falta de informações e instruções sobre estes aspectos.

Com relação às cores dos rótulos, 76,7\% das pessoas afirmaram saber a periculosidade que estas faixas demonstram, porém somente $41,3 \%$ delas acertaram a ordem das classes toxicológicas das quatro faixas, 26,1\% tiveram 2 acertos; $28,3 \%$ tiveram somente um acerto e 4,3\% não tiveram acertos. Waichman et al. (2007), ao entrevistarem pequenos agricultores do estado do Amazonas, contataram que os mesmos não foram capazes de distinguir a toxicidade dos agrotóxicos pelo sistema de codificação de cores. 
Foram apresentadas aos agricultores, seqüências com seis pictogramas diferentes dos EPIs. Dos produtores questionados, $86,7 \%$ que afirmaram saber o significado das figuras, mas apenas $11,5 \%$ acertaram toda a seqüência. Mesmo afirmando saber ou não o significado das figuras, muitos produtores mencionavam não dar atenção a elas, apesar de as considerarem importantes.

O principal motivo de $40 \%$ dos entrevistados não entenderem os rótulos é o uso de termos técnicos difíceis de serem entendidos (79,2\%). O tamanho da letra foi outro motivo citado por $29,2 \%$ dos entrevistados. Estes mesmos motivos foram citados em outros estudos como as principais dificuldades para a leitura e compreensão dos rótulos de agrotóxicos por produtores rurais entrevistados no Estado do Amazonas e Mato Grosso do Sul (WAICHMAN et al., 2007; RECENA; CALDAS, 2008).

Os entrevistados contribuíram dando sugestões para a melhoria dos rótulos, os quais são citados a seguir: uso de uma linguagem mais simples na elaboração de rótulos; rótulos com letras maiores; informações quanto aos riscos que o produto oferece destacadas com letras maiores; maior conteúdo sobre orientações de segurança; as informações de dosagem com maior clareza e detalhadas; rótulos mais fáceis de serem manuseados; informações de interação entre produtos; pictogramas maiores e mais fáceis de serem compreendidos; rótulos com informações mais objetivas; maior destaque da carência do produto e validade.

Os produtores rurais necessitam de mais instruções, apoio e conscientização em relação ao uso de E.P.I.s e os riscos que estes produtos oferecem. Com este trabalho pode ser observado, além de aspectos ligados ao questionário aplicado, outros fatores, que ajudam a concluir a situação geral dos produtores. Percebeu-se a falta de apoio em relação à capacitação dos produtores para uma utilização mais segura de agrotóxicos.
Os resultados evidenciam que faltam esclarecimentos aos produtores sobre a importância do uso de equipamentos de proteção individual, periculosidade dos agrotóxicos e intoxicações. Treinamentos mostrando a importância destes aspectos deveriam ser constantes. Verificou-se também que os rótulos necessitam de mudanças para se tornarem mais fáceis de serem compreendidos pelos produtores, contendo uma linguagem mais simplificada e letras maiores, entre outras sugestões dadas pelos mesmos. Os fabricantes poderiam desenvolver um trabalho acatando sugestões, reclamações e avaliando as dificuldades e carências dos agricultores visando melhoria para ambos.

Os produtores do CEASA não possuíam muito tempo para entrevistas, por isso a elaboração de um questionário objetivo, mas que abordasse questões importantes, abrangeria maior número de entrevistados.

Em relação à abordagem, que era realizada por meio através de uma carta de apresentação, os produtores não demonstraram resistência nem receio para responderem os questionários.

\section{Conclusões}

Os principais motivos para a dificuldade de leitura e compreensão do conteúdo dos rótulos e bulas de agrotóxicos foram os termos técnicos utilizados e o tamanho reduzido das letras das informações.

Os pictogramas, as faixas de cores e termos importantes para a segurança na utilização de agrotóxicos não foram compreendidos pela maioria dos agricultores.

Os inseticidas foram relatados como os principais causadores de intoxicações. 


\section{Referências}

AGOSTINETTO, D.; PUCHALSKI, L. E. A.; AZEVEDO, R.; STORCH, G.; BEZERRA, A. J. A.; GRÜTZMACHER, A. D. Utilização de equipamentos de proteção individual e intoxicações por agrotóxicos entre fumicultores do município de Pelotas-RS. Revista de Ecotoxicologia e Meio Ambiente, Curitiba, v. 8, p. 45$56,1998$.

- Caracterização da fumicultura no município de Pelotas-RS. Revista Brasileira de Agrociência, Pelotas, v. 6, n. 2, p. 171-175, 2000.

ALMEIDA, V. E. S.; CARNEIRO, F. F.; VILELA, N. J. Agrotóxicos em hortaliças: segurança alimentar, riscos socioambientais e políticas públicas para promoção da saúde. Tempus Actas de Saúde Coletiva, Brasília, v. 4, n. 4, p. 84-99, 2009.

ARAÚJO, A. C. P.; NOGUEIRA, D. P.; AUGUSTO, L. G. S. Impacto dos praguicidas na saúde: estudo da cultura de tomate. Revista de Saúde Pública, São Paulo, v. 34, n. 3, p. 309-313, 2000.

ASSOCIAÇÃO NACIONAL DE DEFESA VEGETAL - ANDEF. Manual de uso seguro de produtos fitossanitários. Disponível em: <www.andef.com.b/uso seguro>. Acesso em: 10 nov. 2005.

BLECHER, B. Suicídios apavoram as cidades do fumo. Folha de São Paulo, São Paulo, p. 3, 29, nov. 1996.

BRUM, A. J. Modernização da agricultura - trigo e soja. Petrópolis: Vozes, 1988. 200 p.

CASADO, V. Falta de informação aumenta perigo de agrotóxicos. Folha de Londrina, Londrina, 2, abr. 2005, Folha Rural, p. 4-5.

\section{CONFEDERAÇÃO NACIONAL DOS}

TRABALHADORES NA AGRICULTURA - CONTAG.

Notas oficiais, 2005. Disponível em : <www.contag.org. br>. Acesso em: 25 ago. 2005.

DELGADO, I. F.; PAUMGARTTEN, F. J. R. Intoxicações e usos de pesticidas por agricultores do Município de Paty do Alferes, Rio de Janeiro, Brasil. Caderno de Saúde Pública, Rio de Janeiro, v. 20, n. 1, p. 180-185, 2004.

FARIA, N. M. X.; FACCHINI, L. A.; FASSA, A. G.; TOMASI, E. Processo de produção rural e saúde na serra gaúcha: um estudo descritivo. Caderno de Saúde Pública, Rio de Janeiro, v. 16, n. 1, p. 115-128, 2000.

Trabalho rural e intoxicações por agrotóxicos. Caderno de Saúde Pública, Rio de Janeiro, v. 20, n. 5, p. 1298-1308, 2004.

MONQUEIRO, P. A.; INÁCIO, E. M.; SIlVA, A. C. Levantamento de agrotóxicos e utilização de equipamento de proteção individual entre os agricultores da região de araras. Arquivos do Instituto Biológico, São Paulo, v. 76, n. 1, p. 135-139, 2009.

OLIVEIRA-SILVA, J. J.; ALVES, S. R.; MEYER, A.; PEREZ, F.; SARCINELLI, P. N.; MATTOS, R. C. O. C.; MOREIRA, J. C. Influência de fatores socioeconômicos na contaminação por agrotóxicos, Brasil. Revista de Saúde Pública, São Paulo, v. 35, n. 2, p.130-135, 2001.

ORGANIZAÇÃO PAN-AMERICANA DA SAÚDE - OPAS/OMS. Manual de vigilância da saúde de populações expostas a agrotóxicos. Ministério da Saúde, Secretaria de Vigilância Sanitária. Brasília: Organização Pan-Americana da Saúde/OMS, 1996.

RECENA, M. C. P.; CALDAS, E. D. Percepção de risco, atitudes e práticas no uso de agrotóxicos entre agricultores de Culturama, MS. Revista de Saúde Pública, São Paulo, v. 42, n. 2. p. 294-391, 2008.

SECRETARIA DE ESTADO DE SAÚDE DO PARANÁ - SESA. Saúde do trabalhador. Curitiba: SESA, 2005. Disponível em: <www.saúde.pr.gov.br>. Acesso em: 25 ago. 2005.

WAICHMAN, A.V.; ROMBKE, J.; RIBEIRO, M. O. A.; NAILSON, C. S.; NINA, N. C. S. Use and fate of pesticides in the amazon state, brazil:risk to human health and the environment. Environmental Science and Pollution Research, Berlin, v. 9, n. 6, p. 423-428, 2002. 
